\title{
APPROXIMATION OF CHARACTERISTIC POLYNOMIAL OF SPDTM
}

\author{
Kostic, A.
}

Abstract: In this note we present a modified Newton's method for computing the smallest eigenvalue $\lambda_{1}$ of a symmetric positive definite Toeplitz matrix (SPDTM) . This method based of the Taylor series characteristic polynomial of a SPDTM and respectively the even and odd characteristic polynomials of a SPDTM. The characteristic polynomial (and respectively the even and odd characteristic polynomials) has been approximated with the polynomial of the second order from the Taylor series because it is easy to develop $p_{n}(\lambda)^{\prime \prime}\left(p_{n}^{e}(\lambda)^{\prime \prime} \& p_{n}^{o}(\lambda)^{\prime \prime}\right)$ from specific structure Toeplitz matrix from Gohberg-Simencul formulae.

Key words: eigenvalue problem, Toeplitz matrix, modified Newton's method, even and odd characteristic polynomials
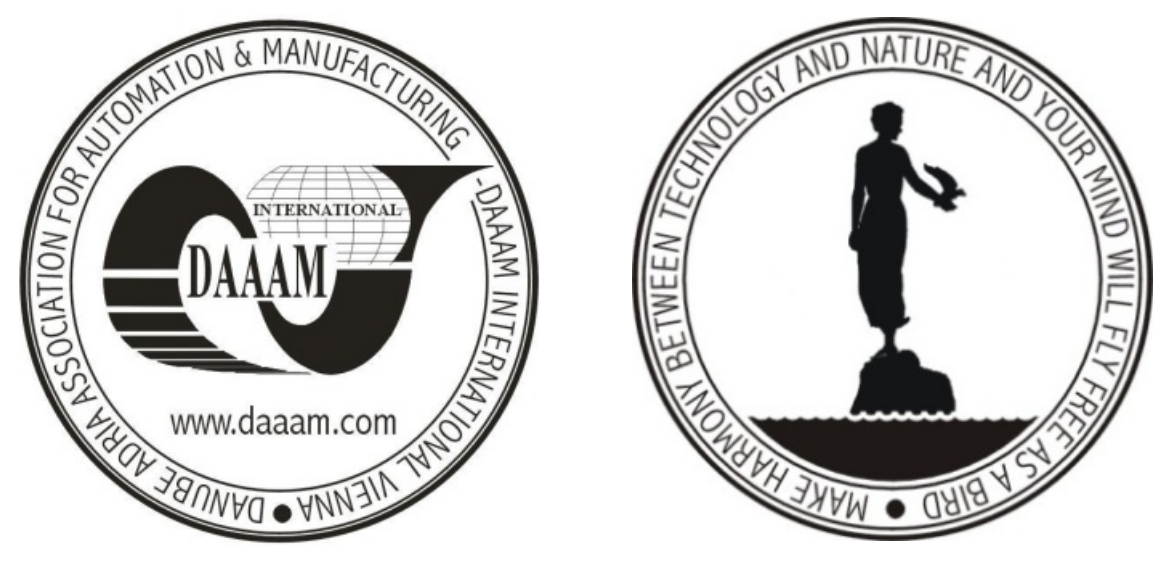

Authors' data: Univ. Asistant Prof. Dr.Sc. Kostic, A[leksandra], University of Sarajevo, Faculty of Mechanical Engineering, Vilsonovo setaliste 9, 71 000, Sarajevo, Bosnia and Herzegovina, kostic@mef.unsa.ba,

This Publication has to be referred as: Kostic, A[leksandra] (2009). Approximation of Characteristic Polynomial of SPDTM , Chapter 09 in DAAAM International Scientific Book 2009, pp. 071-080, B. Katalinic (Ed.), Published by DAAAM International, ISBN 978-3-901509-69-8, ISSN 1726-9687, Vienna, Austria DOI: $10.2507 /$ daaam.scibook.2009.09 